\title{
KARAKTERISTIK FISIK KOMPOS TABLET SLOW RELEASE BERBAHAN DASAR BIOSLURY KOTORAN SAPI
}

\author{
Erni Romansyah ${ }^{1 *}$, Karyanik', Muhammad Fitrah', Mohammad Saharudin' \\ ${ }^{1}$ Program Studi Teknik Pertanian, Universitas Muhammadiyah Mataram, Indonesia \\ co-author: erniroman@gmail.com
}

\begin{tabular}{l} 
Paper Information \\
History: \\
Received : 13-08- 2020 \\
Accepted : 22-09-2020 \\
\hline
\end{tabular}

Keywords:

Physical characteristic Slow release tablet Bioslurry

Hardness

characteristics

\begin{abstract}
Abstrak: Pengembangan kompos tablet slow release dapat dijadikan sebagai salah satu solusi pengelolaan bioslurry kotoran sapi oleh peternak. Bioslurry merupakan produk reject dari pengolahan limbah menjadi biogas. Tujuan penelitian ini adalah untuk mengetahui karakter fisik kompos tablet berbahan dasar bioslurry kotoran sapi. Rancangan penelitian menggunakan Rancangan Acak Lengkap (RAL) dengan dua faktor yaitu komposisi penambahan hydrogel dan silika dari limbah geothermal letusan Gunung Rinjani dengan 5 taraf perlakuan yaitu; T1 (30gr hydrogel : $50 \mathrm{gr}$ silika bubuk); T2 (60gr hydrogel : 40gr silika bubuk); T3 (90gr hydrogel : 30gr silika bubuk); T4 (120gr hydrogel : 20gr silika bubuk); T5 (150gr hydrogel : 10gr silika bubuk). Hasil penelitian menunjukkan bahwa dimensi, bobot, dan kekerasan kompos tablet tidak berbeda nyata. Dimana, perlakuan tanpa penambahan hydrogel memiliki nilai kekerasan paling tinggi. Semakin tinggi penambahan hydrogel maka nilai kekerasan kompos tablet semakin rendah.

Abstract: The development Slow Release Compost Tablet can be used as a solution for the management of cow dung bioslurry by farmers. Bioslurry is a reject product from processing waste into biogas. The purpose of this study was to determine the physical characteristics of tablet compost made from cow dung Bio-slurry. The research design used a completely randomized design (CRD) with two factors, namely the composition of the addition of hydrogel and silica from geothermal waste from the eruption of Mount Rinjani with five levels of treatment, namely; T1 (30gr hydrogel : 50gr silica powder); T2 (60gr hydrogel: 40gr silica powder); T3 (90gr hydrogel : 30gr silica powder); T4 (120gr hydrogel : 20gr silica powder); T5 (150gr hydrogel: 10gr silica powder). The results showed that the dimensions, weight, and hardness of tablet compost were not significantly different. The treatment without the addition of hydrogel has the highest hardness value. The higher the hydrogel addition, the lower the tablet compost hardness value.
\end{abstract}

\section{A. LATAR BELAKANG}

Bioslurry (Mahdi et al., 2010) pada dasarnya merupakan pupuk organik dengan kualitas tinggi yang kaya kandungan hara (Smith et al., 2014). Tidak hanya memiliki kandungan nutrisi yang baik dan lengkap, pupuk bioslurry juga mengandung mikroba (Nurhayati \& Darwati, 2014), yaitu "Pro-Biotik" yang bermanfaat untuk meningkatkan kesuburan dan kesehatan lahan pertanian (La Habi, 2015). Pemanfaatan bioslurry biasanya digunakan untuk pemupukan aneka tanaman pangan, sayuran, bunga, buah dan tanaman perkebunan. Bioslurry adalah produk yang telah mengalami fermentasi anaerob sehingga langsung dapat digunakan untuk memupuk tanaman (Nenobesia et al., 2017). Bioslurry yang berasal dari biogas sangat baik untuk dijadikan pupuk karena mengandung berbagai mineral yang dibutuhkan tanaman. Bioslurry padat diaplikasikan oleh petani dalam bentuk curah. Bioslurry yang ada dalam bentuk curah (Hartatik \& Setyorini, 2012) ini meyulitkan petani untuk aplikasinya (V. Darwis \& Rachman, 2013) karena tidak semua petani mengetahui dosis pemberian pupuk per tanaman.
Adanya pupuk kompos tablet berbahan baku bioslurry kotoran sapi dapat dijadikan solusi untuk memudahkan petani dalam pengaplikasian pupuk pada tanaman.

Sebelum diaplikasikan di lapangan atau dimanfaatkan oleh petani, perlu dilakukan riset terlebih dahulu mengenai komposisi kompos tablet yang paling tepat dengan aplikasi penambahan hydrogel (Nasution et al., 2019) dan silika serta karakteristik fisik kompos tablet. Penambahan hydrogel (D. Darwis et al., 2011) dimaksudkan agar nutrisi kompos yang tercuci saat pemberian irigasi dapat disimpan sementara waktu sampai digunakan oleh akar tanaman. Sementara penambahan silika limbah geothermal (Wahyudi \& Muljani, 2019) letusan Gunung Rinjani dimaksudkan untuk menambah nutrisi mikro ke dalam kompos tablet. Tujuan pembuatan kompos tablet adalah guna mempermudah penyimpanan pupuk dan nantinya akan lebih efisien dalam penggunaannya. Adapun tujuan penelitian ini adalah untuk mengetahui kualitas fisik kompos tablet berbahan dasar bioslurry kotoran sapi.

Proses pembuatan pupuk organik tablet diawali dengan pengeringan bioslurry padat dengan cara dikering anginkan kemudian dihaluskan dan diayak 
untuk menyamakan ukuran. Bioslurry yang sudah dihaluskan kemudian diberi tambahan hydrogel merek Aquakepper yang dibeli di Lab kimia dan silika limbah geothermal yang diperoleh dari Lombok Utara sesuai perlakuan yaitu To kontrol (o gr hydrogel : o gr silika bubuk); T1 (30 gr hydrogel : 50 gr silika bubuk); T2 (60 gr hydrogel : 40 gr silika bubuk); T3 (90 gr hydrogel : 30 gr silika bubuk); T4 (120 gr hydrogel : 20 gr silika bubuk); T5 (150 gr hydrogel : 10 gr silika bubuk) dan dibentuk menjadi tablet dengan alat pencetak kompos tablet. Bioslurry yang sudah menjadi tablet kemudian dikeringkan kembali. Setelah dikeringkan maka kompos tablet dianalisa karakter fisiknya.

\section{B. METODE PENELITIAN}

\section{Waktu dan tempat penelitian}

Penelitian ini telah dilaksanakan pada tanggal 25 Juli sampai 10 Agustus 2020 di LAboratorium Teknik Pertanian Universitas Muhammadiyah Mataram dan Laboratorium Bioproses Fakultas Teknologi Pangan dan Agroindustri Universitas Mataram.

\section{Alat dan bahan penelitian}

Bahan-bahan yang digunakan dalam penelitian ini adalah bioslurry kotoran sapi, tepung kanji sebagai perekat, hydrogel merk dagang Aquakeeper (Lot No. UF $6376 \mathrm{KM}$ ), dan akuades.

Alat-alat yang digunakan dalam penelitian ini adalah alat pencetak kompos tablet (rakitan sendiri), timbangan, sarung tangan, sendok pengaduk, ember, oven, penetrometer, jangka sorong, dan alat tulis.

\section{Metode Penelitian}

Penelitian ini menggunakan rancangan acak lengkap dua faktor, yaitu variasi penambahan hydrogel dan penambahan silika limbah geothermal letusan Gunung Rinjani yang sudah berbentuk bubuk diperoleh dari Lombok Utara yang dirancang dalam perlakuan dengan dasar perhitungan kebutuhan pupuk untuk tanaman padi sebesar 3,5 ton/ha (Juarsah, 2014). Penelitian dilakukan dengan 1 kontrol dan 5 perlakuan dengan ulangan sebanyak 3 kali sehingga diperoleh 18 sampel percobaan (lihat Tabel 1).

Tabel 1.

\section{Rancangan Percobaan}

\begin{tabular}{|c|c|c|c|c|}
\hline Kode & $\begin{array}{c}\text { Bioslurry } \\
(\mathrm{g})\end{array}$ & $\begin{array}{c}\text { Hydrogel } \\
(\mathrm{g})\end{array}$ & $\begin{array}{c}\text { Silika } \\
(\mathrm{g})\end{array}$ & Perekat \\
\hline $\mathrm{T} 0$ & 350 & 0 & 0 & $5 \%$ \\
\hline $\mathrm{T} 1$ & 350 & 30 & 50 & $5 \%$ \\
\hline $\mathrm{T} 2$ & 350 & 60 & 40 & $5 \%$ \\
\hline $\mathrm{T} 3$ & 350 & 90 & 30 & $5 \%$ \\
\hline $\mathrm{T} 4$ & 350 & 120 & 20 & $5 \%$ \\
\hline $\mathrm{T} 5$ & 350 & 150 & 10 & $5 \%$ \\
\hline
\end{tabular}

\section{Pelaksanaan Penelitian}

\subsection{Persiapan bioslurry}

Bahan dasar kompos tablet menggunakan bioslurry yang diambil dari limbah biogas kotoran sapi yang diperoleh dari instalasi biogas penduduk di Desa Ubung Kecamatan Lombok Tengah. Adapun Langkah-langkah persiapannya sebagai berikut (Sunaryo, 2014):

1. Limbah bioslurry diambil dari bagian outlet instalasi biogas

2. Dipisahkan dengan limbah cairnya, hanya diambil limbah padatnya

3. Kemudian limbah padat bioslurry dikering anginkan selama 24 jam

4. Setelah kering kemudian diayak dengan ayakan ukuran 20 mesh untuk menyeragamkan ukuran

5. Limbah padat bioslurry siap digunakan untuk pembuatan kompos tablet

6. Pembuatan Kompos tablet

Setelah semua bahan disiapkan, pembuatan kompos tablet dicampur sesuai perlakuan yang telah ditentukan sebelumnya. Adapun tahapantahapannya adalah

1. Disiapkan bioslury, hydrogel, silika, perekat, dan air

2. Ditimbang bioslurry, hydrogel, silika, dan bahan perekat sesuai perlakuan

3. Semua bahan dimasukkan kedalam ember

4. Dicampurkan semua bahan dan ditambahkan air secukupnya

5. Diaduk sampai semua bahan tercampur merata

6. Dituang adonan kompos ke dalam mesin pencetak kompos tablet

7. Adonan siap dicetak

Setelah dicetak, selanjutnya dikeringkan/dijemur selama 1 hari agar kompos tablet menjadi padat

\subsection{Pengujian Sifat Fisik Kompos Tablet}

Setelah kompos tablet selesai dibuat, selanjutnya akan diuji sifat fisik (Utami et al., 2008) dari kompos tablet tersebut dengan mengukur beberapa parameter seperti dimensi, kadar air, dan kekerasan kompos tablet. Adapun cara pengukuran parameter fisik dijelaskan sebagai berikut.

\subsubsection{Dimensi}

Masing-masing sampel diukur dimensinya (Panjang, lebar, tebal) menggunakan penggaris dan jangka sorong.

\subsubsection{Kadar Air}

Pengukuran kadar air dilakukan dengan menggunakan metode gravimetri. Masing-masing sampel ditimbang beratnya kemudian dioven menggunakan oven merk Memmert pada suhu $105^{\circ} \mathrm{C}$ selama 24 jam. Selanjutnya ditimbang berat akhir dan dihitung kadar airnya dengan rumus: 
Jurnal Agrotek Ummat Vol. 7 No.2 2020/Karakteristik Fisik Kompos Tablet Slow Release Berbahan Dasar Bioslurry Kotoran Sapi/Erni Romansyah, Karyanik, Muhammad Fitrah, Mohammad Saharudin

$$
K a=\frac{a-b}{a} \times 100 \%
$$

Dimana: $\mathrm{a}=$ berat awal $(\mathrm{g})$

$$
\mathrm{b}=\text { berat akhir }(\mathrm{g})
$$

\subsubsection{Kekerasan}

Pengujian kekerasan dilakukan dengan menggunakan alat penetrometer merk Brookfield di laboratorium bioproses FATEPA UNRAM. Masing-masing sampel diuji tingkat kekerasannya kemudian dibandingkan.

\section{Diagram Alir Pelaksanaan Penelitian}

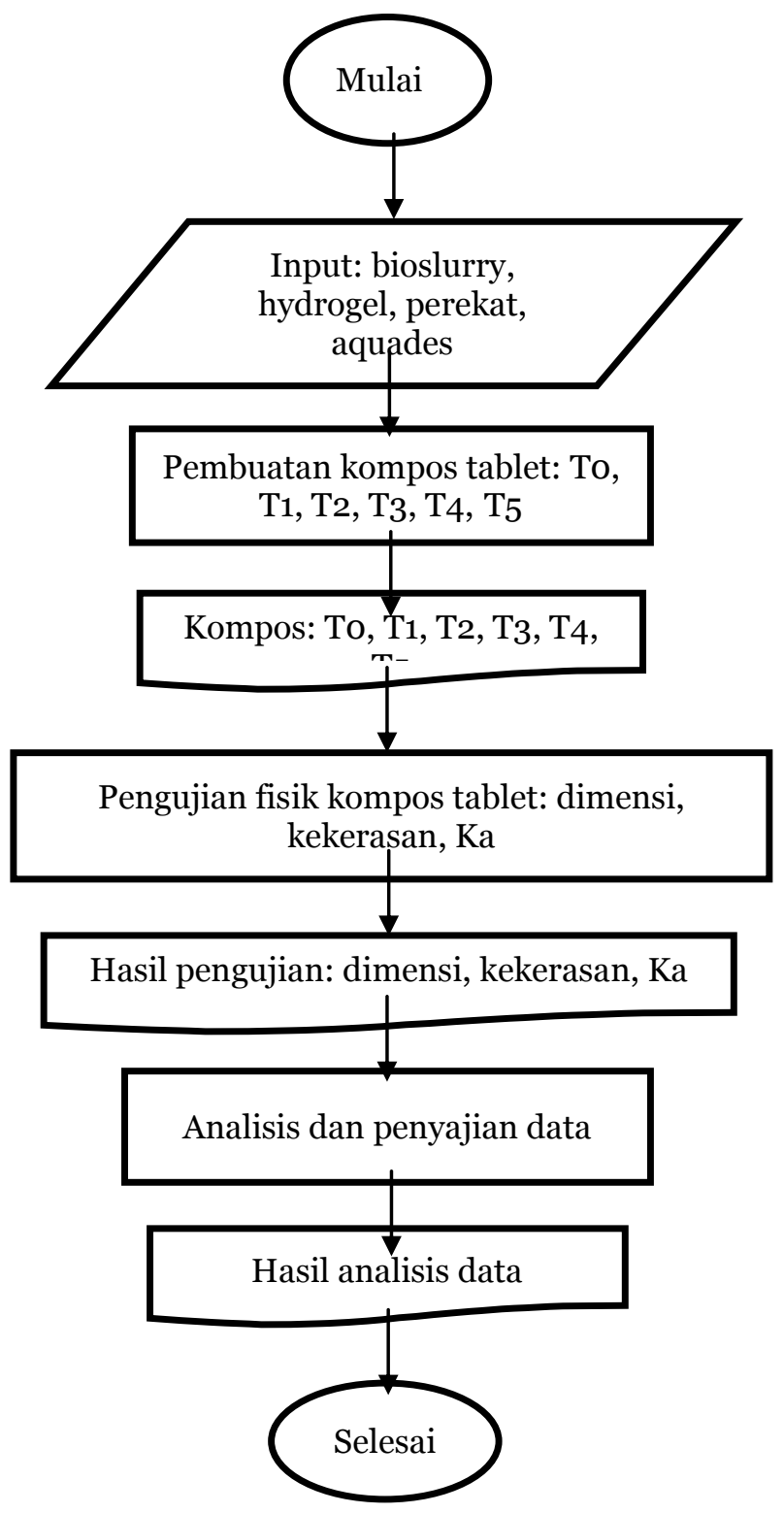

Gambar 1. Diagram alir proses penelitian

\section{HASIL DAN PEMBAHASAN}

Karakteristik fisik kompos tablet (Kusuma \& Apriliani, 2018) digambarkan dengan mendefinisikan beberpa parameter hasil pengamatan (Fadhilah \& Saryanti, 2019) seperti dimensi, kekerasan, bobot per tablet, dan tingkat kekeruhan saat pengujian daya larut kompos tablet.

\section{Dimensi}

Ada tiga parameter yang diamati untuk menggambarkan dimensi dari kompos tablet yaitu bobot tablet, diameter tablet, dan tinggi tablet. Berikut disajikan grafik hasil pengukuran dimensi kompos tablet.

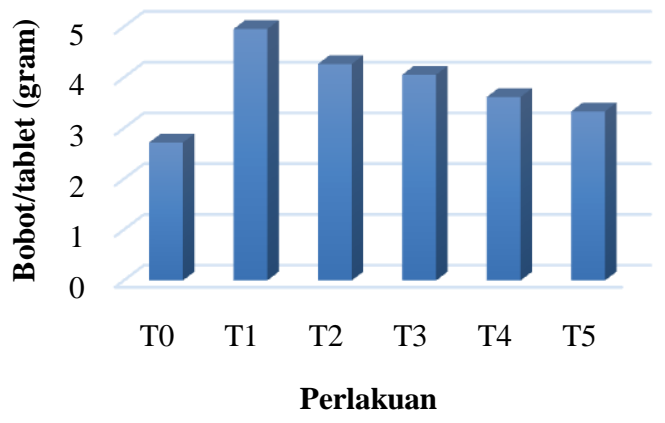

Gambar 2. Bobot kompos tablet per butir

Berdasarkan Gambar 2 dapat dilihat bahwa bobot per butir kompos tablet hasil pencetakan bervariasi, meskipun ukuran dimensi pencetak kompos per lubang semuanya sama. Hal ini dikarenakan adanya penambahan hydrogel yang bervariasi. Bobot kompos kering yang paling tinggi diperoleh pada perlakuan $\mathrm{T} 1$ yaitu 4,96 gr dengan penambahan 30 gr hydrogel dalam setiap 350 gr bioslurry. Bobot terendah pada perlakuan T5 yaitu 3,33 gr dengan penambahan 150 gr hydrogel dalam setiap 350 gr bioslurry. Sementara perlakuan control To memiliki bobot yang lebih rendah dari perlakuan T1 sampai T5. Kesimpulannya, semakin tinggi penambahan hydrogel maka bobot kering kompos tablet per butir menjadi semakin rendah. Hal ini karena hydrogel yang digunakan memiliki daya ngembang sampai $0,0095 \mathrm{gr} /$ menit sehingga pada saat dikeringkan, air yang sudah diserap oleh hydrogel akan menguap dan bobot kompos tablet menjadi berkurang. Hal ini sesuai dengan pendapat (Ahmed, 2015) yang menyatakan bahwa hidrogel setelah terkena air mampu menyerap dan mengembang hingga beberapa kali lipat volumenya dari bentuk saat kering sehingga pada saat dikeringkan maka volume dan bobotnya akan kembali ke bentuk semula.

Selanjutnya adalah diameter tablet. Berdasarkan Gambar 3 nampak bahwa diameter kompos tablet tertinggi diperoleh pada perlakuan T1 yaitu 1,97 cm dan diameter terendah pada perlakuan $\mathrm{T}_{5}$ yaitu $1,84 \mathrm{~cm}$. Perlakuan kontrol To memiliki diameter yang lebih rendah dari perlakuan $\mathrm{T} 1$ sampai $\mathrm{T} 5$ Penambahan hydrogel berkorelasi negative terhadap diameter kompos tablet kering. 


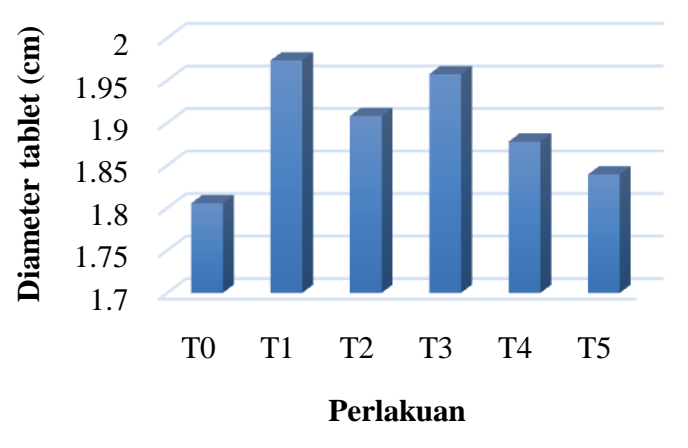

Gambar 3. Diameter kompos tablet per butir

Dimensi terkahir adalah tinggi tablet. Dimana, tinggi kompos tablet tertinggi diperoleh pada perlakuan T1 yaitu 2,13 $\mathrm{cm}$ dan diameter terendah pada perlakuan T5 yaitu $1,87 \mathrm{~cm}$. Sementara perlakuan kontrol To juga memiliki tinggi yang lebih rendah dari perlakuan T1 sampai $\mathrm{T}_{5}$. Penambahan hydrogel juga berkorelasi negative terhadap tinggi kompos tablet kering. Secara keseluruhan hasil pengukuran dimensi, semakin tinggi penambahan hydrogel maka dimensi kompos tablet kering yang dihasilkan semakin rendah.

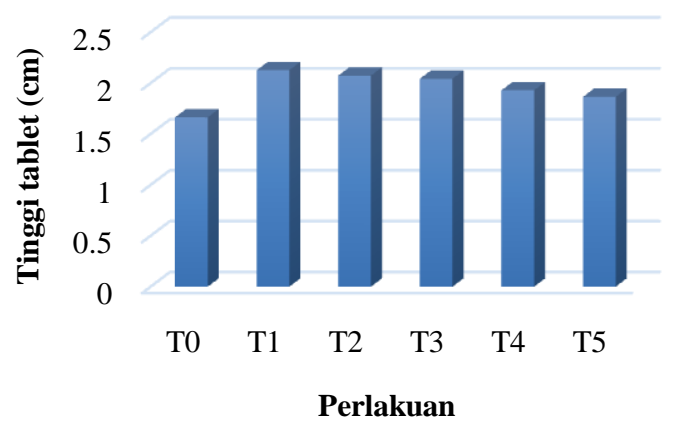

Gambar 4. Tinggi kompos tablet per butir

\section{Kadar air}

Kadar air kompos tablet setelah kering bervariasi karena proses pengeringan dilakukan secara alami dibawah sinar matahari selama kurang lebih dua hari. Berikut ditampilkan grafik hasil pengukuran kadar air kompos tablet basis basah.

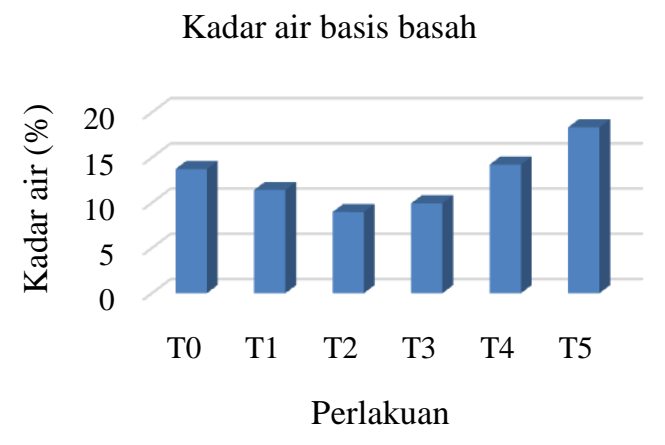

Gambar 5. Kadar air kompos tablet

Berdasarkan Gambar 5 diketehaui bahwa kadar air kompos tablet kering tertinggi diperoleh pada perlakuan
T5 yaitu $18,35 \%$ dan kadar air terendah pada perlakuan T2 yaitu 8,98 \%. Semakin tinggi penambahan hydrogel maka kadar airnya semakin tinggi karena masih ada air terikat yang terperangkap di dalam hydrogel.

\section{Kekerasan}

Kekerasan menggambarkan besarnya tekanan yang dibutuhkan untuk menghancurkan kompos tablet atau seberapa besar daya yang dibutuhkan (Putri \& Husni, 2018). Uji kekerasan tablet mengambarkan kekuatan tablet yang berhubungan dengan kekuatan ikatan partikel pada bagian tepi atau permukaan tablet (Fadhilah \& Saryanti, 2019)( et al., 2016). Hasil uji kekerasan kompos tablet dapat dilihat pada Gambar 6.

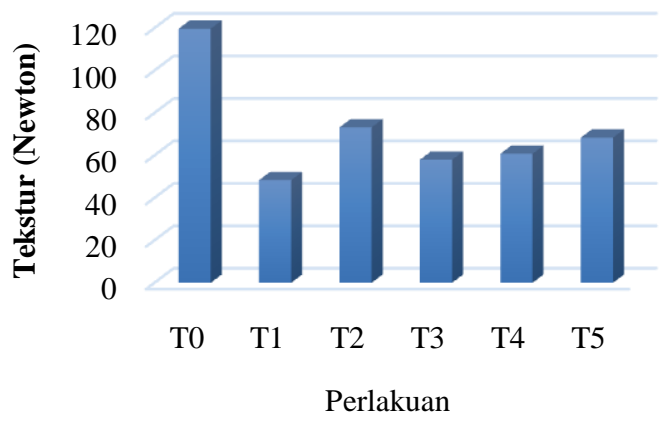

Gambar 6. Nilai tekstur kompos tablet

Berdasarkan Gambar 6 diketahui bahwa nilai tekstur kompos tablet tertinggi diperoleh pada perlakuan tanpa pemberian hydrogel yaitu To yaitu 119,66 Newton. Penambahan hydrogel membuat kompos tablet menjadi agak lunak dan elastis sehingga lebih mudah dihancurkan. Hal ini berarti semakin tinggi nilai tekstur maka semakin susah kompos tablet tersebut dihancurkan.

\section{KESIMPULAN}

Berdasarkan hasil penelitian yang telah dilakukan, dapat ditarik beberapa kesimpulan sebagai berikut:

1. Karakteristik kompos tablet terbaik diperoleh pada perlakuan $\mathrm{T} 1$ yaitu dengan penambahan $30 \mathrm{gr}$ hydrogel

2. Perlakuan tanpa penambahan hydrogel memiliki nilai kekerasan paling tinggi.

3. Semakin tinggi penambahan hydrogel maka nilai tekstur dan dimensi kompos tablet semakin rendah.

\section{UCAPAN TERIMA KASIH}

Penulis mengucapkan terima kasih kepada DRPM Ristek DIKTI yang telah memberikan dana untuk melaksanakan penelitian ini tanpa kurang satu apapun.

\section{DAFTAR RUJUKAN}

Ahmed, E. M. (2015). Hydrogel : Preparation, characterization, and applications: A review. In Journal of Advanced 
https://doi.org/10.1016/j.jare.2013.07.006

Darwis, D., Hardiningsih, L., \& Nurlidar, F. (2011). Karakteristik Sifat Fisika - Kimia Hidrogel PVP-Madu-Gliserin Hasil Iradiasi Gamma. Jurnal Ilmiah Aplikasi Isotop Dan Radiasi.

Darwis, V., \& Rachman, B. (2013). Potensi Pengembangan Pupuk Organik Insitu Mendukung Percepatan Penerapan Pertanian Organik. Forum Penelitian Agro Ekonomi. https://doi.org/10.21082/fae.v31n1.2013.51-65

Fadhilah, I. N., \& Saryanti, D. (2019). FORMULASI DAN UJI STABILITAS FISIK SEDIAAN TABLET EKSTRAK BUAH PARE (Momordica charantia L.) SECARA GRANULASI BASAH. Smart Medical Journal https://doi.org/10.13057/smj.v2i1.29676

Hartatik, W., \& Setyorini, D. (2012). Pemanfaatan Pupuk Organik untuk Meningkatkan Kesuburan Tanah dan Kualitas Tanaman. Prosiding Seminar Nasional Teknologi Pemupukan Dan Pemulihan Lahan Terdegradasi.

Juarsah, I. (2014). Pemanfaatan pupuk organik untuk pertanian organik dan lingkungan berkelanjutan. Prosiding Seminar Nasional Pertanian Organik.

Kusuma, D., \& Apriliani, E. D. (2018). Evaluasi Fisik Tablet Parasetamol Generik dan Tablet Parasetamol Bermerk Dagang. Jurnal Kefarmasian Akfarindo.

La Habi, M. (2015). PENGARUH APLIKASI KOMPOS GRANUL ELA SAGU DIPERKAYA PUPUK PONSKA TERHADAP SIFAT FISIK TANAH DAN HASIL JAGUNG MANIS DI INCEPTISOL. BIOPENDIX: Jurnal Biologi, Pendidikan Dan Terapan. https://doi.org/10.30598/biopendixvol1issue2page126-139

Mahdi, S. S., Hassan, G. I., Samoon, S. a., Rather, H. a., Dar, S. a., \& Zehra6, B. (2010). Bio-Fertilizers In Organic Agriculture. Journal of Phytology.

Nasution, P. S., Hamimdal, M. A., Syahbirin, G., \& Arifin, B. (2019). Optimalisasi Sifat Reologi Hidrogel KitosanHialuronat yang Ditaut-Silang dengan Glutaraldehida. ALCHEMY Jurnal Penelitian Kimia. https://doi.org/10.20961/alchemy.15.1.22536.24-43

Nenobesia, D., Mellab, W., \& A, P. S. (2017). Pemanfaatan Limbah Padat Kompos Kotoran Ternak dalam Meningkatkan Daya Dukung Lingkungan dan Biomassa Tanaman Kacang Hijau (Vigna radiata L.). Jurnal Lingkungan Hidup.

Nurhayati, H., \& Darwati, I. (2014). Peran mikroorganisme dalam mendukung pertanian organik. Prosiding Seminar Nasional Pertanian Organik.

Putri, Y. K., \& Husni, P. (2018). Pengaruh Bahan Pengikat Terhadap Fisik Tablet. Farmaka.

Smith, J., Abegaz, A., Matthews, R. B., Subedi, M., Orskov, E. R., Tumwesige, V., \& Smith, P. (2014). What is the potential for biogas digesters to improve soil carbon sequestration in Sub-Saharan Africa? Comparison with other uses of organic residues. Biomass and Bioenergy. https://doi.org/10.1016/j.biombioe.2014.01.056

Sunaryo. (2014). Rancang bangun reaktor biogas untuk pemanfaatan limbah kotoran ternak sapi di desa limbangan kabupaten banjarnegara. Jurnal PPKM UNSIQ I (2014).

Tambunan, R. M., Rahmat, D., \& Silalahi, J. S. (2016).
FORMULASI TABLET NANOPARTIKEL EKSTRAK TERSTANDAR DAUN PULAI (Alstonia scholaris (L). R. BR) SEBAGAI ANTIDIABETES. Journal Of Tropical Pharmacy And Chemistry. https://doi.org/10.25026/jtpc.v3i4.117

Utami, M. B., Aisyiah, N., Ikhsan, F. M., Lestari, D. P., Fadilah, M., Diana, Nurhidayah, N., Nasocha, E., Retna, O., \& Ibnu, A. D. (2008). Pengukuran Compressive Strength Benda Padat. Fakultas Sains Dan Teknologi Universitas Airlangga.

Wahyudi, B., \& Muljani, S. (2019). PUPUK MULTINUTRIENT BERBASIS SILIKA DARI LIMBAH GEOTHERMAL SLUDGE DENGAN PROSES ASIDIFIKASI. Jurnal Teknik Kimia. https://doi.org/10.33005/jurnal_tekkim.v14i1.1651 